\title{
The behavioral and neurochemical effects of methylprednisolone or metyrapone in a post-traumatic stress disorder rat model
}

\author{
(1) Ayse Melek Tanriverdi, ${ }^{1}$ (i) Banu Aydin, ${ }^{1}$ (i) Berna Terzioglu Bebitoglu, ${ }^{2}$ (i) Hulya Cabadak, ${ }^{1 *}$ \\ (D) M. Zafer Goren ${ }^{3 *}$ \\ ${ }^{1}$ Department of Biophysics, Marmara University Faculty of Medicine, Istanbul, Turkey \\ 2Department of Medical Pharmacology, Istanbul Medeniyet University Faculty of Medicine, Istanbul, Turkey \\ ${ }^{3}$ Department of Medical Pharmacology, Marmara University Faculty of Medicine, Istanbul, Turkey
}

\begin{abstract}
OBJECTIVE: Mechanisms contributing to the post-traumatic stress disorder (PTSD) that involve several physiological systems, and the activation of the hypothalamic-pituitary-adrenal axis (HPA) is one of the most known systems in the PTSD pathophysiology. The present study investigates the potential effects of methylprednisolone, metyrapone and their association with the noradrenergic system within the rostral pons, a region containing the locus coeruleus (LC) in a rat model of PTSD induced with predator scent.

METHODS: In this study, Sprague-Dawley rats were exposed to the stress by exposure to the scent of dirty cat litter, which is a natural stressor of a predator. One week later, the rats were re-exposed to a situational reminder (clean cat litter). The rats were treated using either methylprednisolone, metyrapone or physiological saline before exposure to a situational reminder ( $n=8$ in each group). Noradrenaline (NA) levels in the rostral pons homogenates were analysed using ELISA.

RESULTS: The anxiety indices of the rats exposed to the trauma were found to be significantly higher than the anxiety indices of the control rats. Metyrapone produced a significant increase in the anxiety indices of the non-stressed rats, and methylprednisolone did not produce a change in the anxiety indices of the non-stressed rats. Methylprednisolone treatment suppressed the anxiety in the stressed rats. Metyrapone treatment increased the anxiety indices in the stressed rats but still being lower than that of the saline-treated stressed rats. Significant decrease in the freezing time was observed following the methylprednisolone treatment both in the stressed and non-stressed rats. NA content in the rostral pons of the stressed rats was significantly higher than that of the non-stressed rats. Methylprednisolone or metyrapone treatments decreased the NA content in the non-stressed rats as compared to the saline treatment. However, these decreases were not significant.
\end{abstract}

CONCLUSION: In this study, findings suggest that stress may give rise to endocrine, autonomic and behavioural responses. The anxiety indices and NA levels in the rostral pons increased with the traumatic event. The methylprednisolone treatment may suppress anxiety through interactions between the LC and the HPA axis.

Keywords: Anxiety index; hypothalamic-pituitary-adrenal axis; locus coeruleus; noradrenaline; rostral pons.

Cite this article as: Tanriverdi AM, Aydin B, Terzioglu Bebitoglu B, Cabadak H, Goren MZ. The behavioral and neurochemical effects of methylprednisolone or metyrapone in a post-traumatic stress disorder rat model. North Clin Istanb 2019;6(4):327-333.

*Equally contributed to the work.

Received: October 08, 2018 Accepted: May 21, 2019 Online: July 17, 2019

Correspondence: Dr. Berna TERZIOGLU BEBITOGLU. İstanbul Medeniyet Üniversitesi, Tıp Fakültesi, Tıbbi Farmakoloji

Anabilim Dalı, İstanbul, Turkey.

Tel: +90 5324114979 e-mail: bernaterzioglu@gmail.com

(c) Copyright 2019 by Istanbul Provincial Directorate of Health - Available online at www.northclinist.com 
Dost-traumatic stress disorder (PTSD) is a serious 1 mood and anxiety problem with important manifestations for the patients, their families and the society [1]. The disease is precipitated by a traumatic event and is characterized by dysfunction in the mood lasting for more than one month and the persistence of signs are experiencing the stress after situational reminders, avoidance behaviours, negative mood changes and hyperarousal or hyper-vigilance with new symptoms, such as increased aggressive behaviour as stated in DSM-V [2].

Response to stress is accompanied by various emotional and physical properties as a result of the activation of several physiological systems [3]. Hypothalamus- pituitary-adrenal axis (HPA) activation is one of the most known responses given to stress and is accused of being involved in the PTSD pathophysiology $[4,5]$. During stress, corticotropin-releasing factor (CRF) acts on the pituitary gland to generate steroids that act on the monoaminergic systems involved in the stress reaction. The limbic structures, such as stria terminalis, and central nucleus of the amygdala that are important in several autonomic and behavioural manifestations of PTSD and CRF mediates anxiety and emotional responses through these systems [6-8].

There are controversial data in the literature regarding the cortisol levels [9-13]. The change in the levels of cortisol may cause false recall of memories in the PTSD. The effects of hydrocortisone administration on automatic memory recall were investigated in a randomized, placebo-controlled study in patients with PTSD. However, hydrocortisone treatment was not found to be different from that of the placebo administration [9].

Noradrenaline (NA) is known to have a role in cognitive functions in several psychiatric disorders $[14,15]$. Recently, the increased NA concentration in the rostral pons of rats demonstrated in a rat model of PTSD [16]. The Locus coeruleus (LC), a region located in the pons is rich in NA-containing neurons. NA is not only involved in the central effects occurring in the brain during stress but it is also critical in bringing on the peripheral autonomic effects. A study also demonstrated that NA concentrations increased in the cerebrospinal fluid following exposure to psychological stress [17]. It was also shown that NA in the LC is usually activated together with the HPA axis activation following the stress exposure; this activation is thought to be mediated by CRF [18]. CRF projections from the central nucleus of the amygdala (CeA) to the LC and the paraventricular nucleus of hy- pothalamus produce excitatory effects and bring about increases in the NA input to the CeA. Cortisol may inhibit noradrenergic activity resulting in the unopposed neuroendocrine response to stress [19].

Metyrapone is an agent that can prevent the synthesis of cortisol. Hence, metyrapone can be used to show the interaction between the NA and the cortisol by removing the (-) negative feedback mechanism. In this setting, we wanted to test the behavioural aspects and the NA concentration in the rostral pons using methylprednisolone or metyrapone in a rat model of PTSD induced with predator scent.

\section{MATERIALS AND METHODS}

\section{Animals}

Female Sprague-Dawley rats weighing 200-250 g were supplied from Marmara University Experimental Animal Center (DEHAMER), and local ethical committee approval $(22.05 .2014,13,2013 . \mathrm{mar})$ was obtained before the experiments. The rats were kept in cages at $21 \pm 3^{\circ} \mathrm{C}$ and $50 \pm 5 \%$ humidity with a reversed $12 \mathrm{~h}$ light/dark cycle for 10 days. The rats were fed with standard food and water ad libitum. All in vivo experimental procedures were performed in the dark phase at 10:00 am with a dim light source. There were six experimental groups where each group contained eight rats. The rats were either stressed or non-stressed and received physiological saline, metyrapone, or methylprednisolone.

\section{Predator Scent Test}

Predator scent test was used in this study to elucidate the PTSD-like manifestations using the scent of dirty cat litter which is a natural stressor of a predator as described previously [20]. The dirty cat litter was obtained from a male cat that used the litter for two days, and the litter was sifted for stools. The rats were kept within plexiglass cages $(30 \mathrm{~cm}$ X $30 \mathrm{~cm} \mathrm{X} 40 \mathrm{~cm})$ containing $150 \mathrm{ml}$ dirty cat litter for $10 \mathrm{~min}$ where the control (nonstressed) group was exposed to clean, unused, fresh cat litter. Following one week after the onset of the stress, the rats were exposed to the clean cat litter that acted as a situational reminder. The behavioural parameters on the elevated plus-maze were scored from the recordings of an overhead video camera. The rats received either saline (physiological saline, PS, $0.1 \mathrm{ml} / 100 \mathrm{~g}$ ) or methylprednisolone $(20 \mathrm{mg} / \mathrm{kg}$; Mustafa Nevzat, Turkey) or metyrapone $(100 \mathrm{mg} / \mathrm{kg}$; Santa Cruz Biotechnology, Inc, 
CA, USA) intraperitoneal injections 10 min before the exposure to a situational reminder (clean cat litter). The effective doses of methylprednisolone or metyrapone were used as stated $[21,22]$. The doses were also checked in preliminary studies.

\section{The Elevated Plus-Maze}

After exposure to the situational reminder, the rats were placed on an elevated plus-maze for five minutes. The elevated plus-maze consists of two open $(50 \mathrm{~cm} \mathrm{X}$ $10 \mathrm{~cm})$ and two closed $(50 \mathrm{~cm}$ X $10 \mathrm{~cm})$ arms. Closed arms were surrounded by $40 \mathrm{~cm}$ long walls, and the height of the maze was $50 \mathrm{~cm}$ from the ground. The labyrinth was cleaned with a $5 \%$ alcohol solution before the placement of rats.

Each rat was placed in the central square of the plusmaze facing the open arms. An arm entry was defined when all four paws were present within the arm. Video recordings were used for the scoring of the entries into the open or the closed arms. The amount of time spent in the open arms provides information regarding the anxiety state of the animal. If anxiety-like feelings of animals are reduced, then, the animal will spend more time in the open arms of the maze. In contrast, animals with anxiety will experience heightened anxiety-like feelings and will spend less time in the open arms of the maze. The number of entries in the open and the closed arms and the total time spent on open arms are noted and the anxiety index $\left(\mathrm{N}_{\text {anxiety }}\right)$ was calculated using the following formula:

$$
\mathrm{N}_{\text {anxiety }}=1-1 / 2[(\mathrm{a} / 300 \mathrm{~s})+(\mathrm{b} / \mathrm{c})]
$$

$(a=$ cumulative time spent in open arms $(s), b=$ open arm entries, $c=$ total arm entries).

The freezing behaviour is defined as the lack of all movements of rats during experiments except for respiration. The cumulative freezing time over a five minutes interval was also recorded in both stressed and nonstressed rats following exposure to the reminder. After completion of experiments, the rats were sacrificed using a high dose of pentobarbital and the selected brain regions were dissected in frozen tissues.

\section{Preparation of the Tissue Samples}

Upon decapitation, the rostral pons found in the brain stem was dissected. The rostral pons contains the dark coloured LC. The tissues were weighed and ground into a homogenate in the presence of ice-cold PBS $(\mathrm{pH}=7.4)$ by adding $200 \mu \mathrm{l}$ per $1 \mathrm{mg}$ tissue sample. After centrifugation at $3000 \mathrm{rpm}\left(4^{\circ} \mathrm{C}\right)$ for $20 \mathrm{~min}$, the supernatant was collected and kept at $-80^{\circ} \mathrm{C}$ until assay. The protein content of the tissue homogenates was measured using the Lowry method [23].

\section{Noradrenaline Assay}

Tissue homogenates were assayed for NA level using the colorimetric method at $450 \mathrm{~nm}$. NA level was detected with Rat Noradrenaline ELISA assay kit (Sunred Biotechnology Company, China), according to the manufacturer's protocol. The NA content in the homogenates was adjusted according to the protein levels in the tissues and expressed as $\mathrm{ng} / \mathrm{mg}$ tissue/mg protein.

\section{Statistical Analysis}

All data were expressed as mean \pm SEM. The anxiety indices and NA levels of the stressed and non-stressed rats were compared using unpaired student's t-test. One-way analysis of variance and the Tukey's post-hoc test were used for the analyses of anxiety indices and freezing times in all groups. For all statistical calculations, significance was accepted where $\mathrm{p}<0.05 . \mathrm{GraphPad}$ Prism $7.0^{\circ}$ is used for statistical analysis (GraphPad Software, San Diego, USA).

\section{RESULTS}

The anxiety indices of the rats exposed to the stress were measured as $(0.86 \pm 0.02)$, and it was found to be significantly higher than the anxiety indices of the control rats $(0.62 \pm 0.05)$ (Fig. 1; (unpaired student's t-test) p<0.05). Metyrapone produced a significant increase in the anxiety indices of the non-stressed rats (Fig. 1; F=5.501; $\mathrm{p}=0.0317)$. Methylprednisolone did not produce a significant change in the anxiety indices of the non-stressed rats $(p=0.9991)$. The anxiety indices of the saline-treated stressed rats were found to be significantly different from that of all other groups (Fig. 1b; $p<0.0001$ ). Methylprednisolone treatment decreased the anxiety indices in the stressed rats (Fig. $1 b ; p<0.0001$ ). These findings indicate that methylprednisolone treatment suppressed anxiety. Metyrapone treatment increased the anxiety indices in the stressed rats but still being lower than that of the saline-treated stressed rats $(p=0.0001)$.

The mean cumulative freezing times in all groups were analysed using one-way analysis of variance and the treatments were found to be the source of variation both 


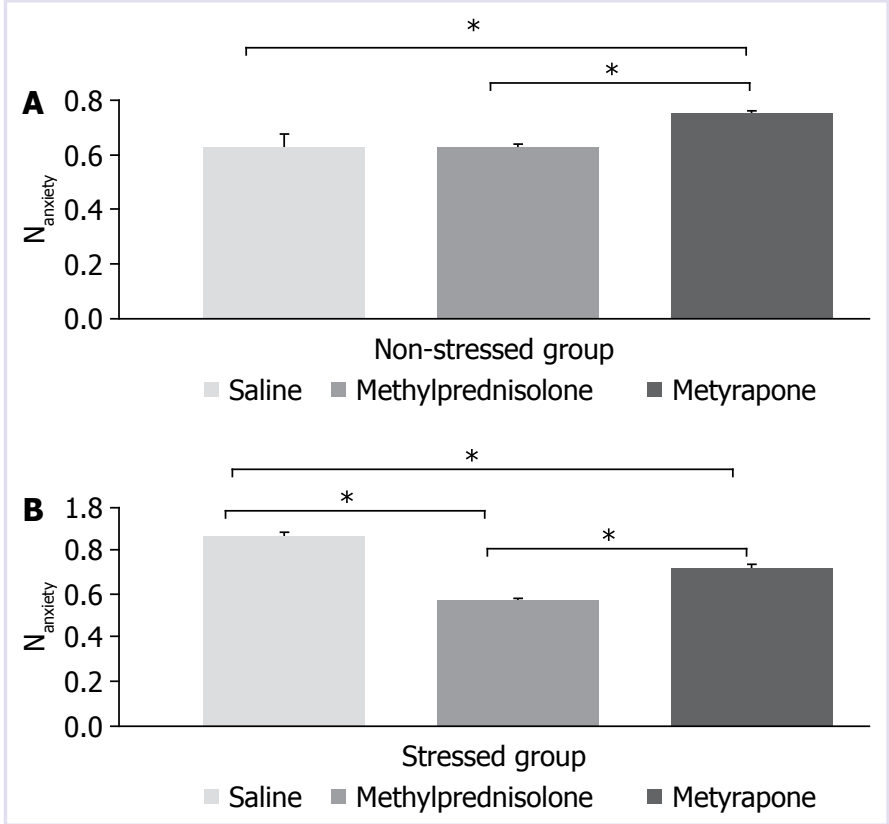

FIGURE 1. Anxiety indices of non-stressed (A) and stressed rats (B) after injection of saline (vehicle) or methylprednisolone $(20 \mathrm{mg} / \mathrm{kg})$ or metyrapone $(100 \mathrm{mg} / \mathrm{kg}), \mathrm{p}<0.05$.



FIGURE2. Cumulative freezing times of non-stressed (A) and stressed rats (B) after injection of saline and or methylprednisolone $(20 \mathrm{mg} / \mathrm{kg})$ or metyrapone $(100 \mathrm{mg} / \mathrm{kg}), \mathrm{p}<0.05$.
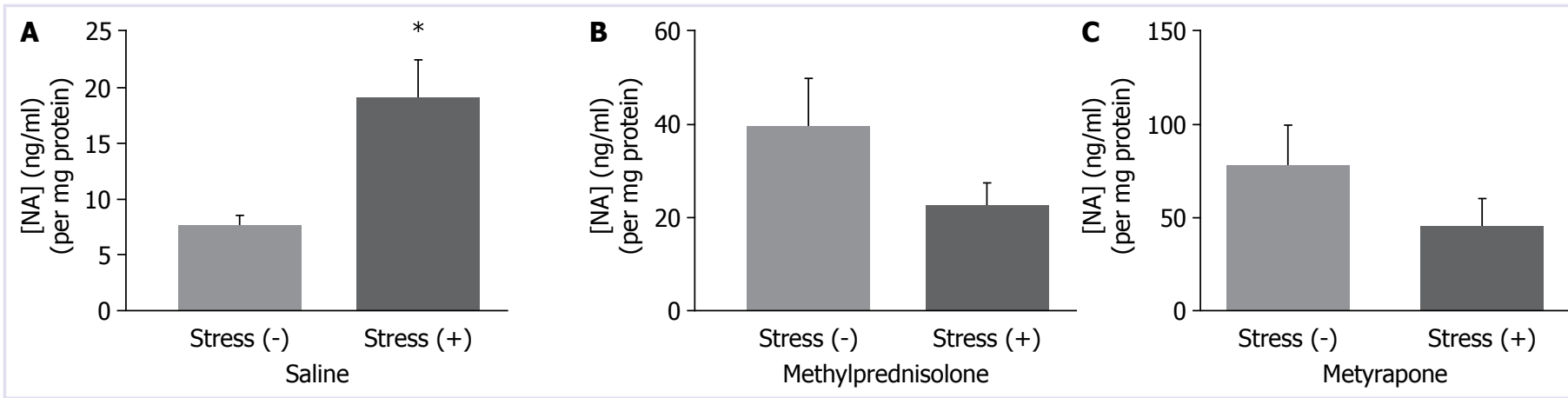

FIGURE 3. Noradrenaline level after saline (A), methylprednisolone (20 mg/kg) (B) and metyrapone (100 mg/kg) (C) injections in stressed and non-stressed rats, $\mathrm{p}<0.05$.

in stressed and non-stressed groups $(\mathrm{F}=3.878 ; \mathrm{p}=0.041$ and $\mathrm{F}=21.21 ; \mathrm{p}<0.0001$, respectively). The post-hoc test detected a significant decrease in the freezing time after methylprednisolone treatment in both stressed and nonstressed rats (Fig. 2A, B; $p=0.0358$ and $p=0.0004$, respectively). Metyrapone treatment did not produce a significant difference from the saline treatment both in the stressed and the non-stressed rats (Fig. 2A, B p $=0.5715$ and $\mathrm{p}=0.2236$, respectively).

The NA level was $7.39 \pm 0.89 \mathrm{pg} / \mathrm{mg}$ in the nonstressed rats, and it increased to $18.89 \pm 3.37 \mathrm{pg} / \mathrm{mg}$ in the stressed rats. NA content in the rostral pons of the stressed rats was significantly higher than that of the non-stressed rats $(p=0.0109)$. The preventive effects of drug treatments on NA levels following the exposure of the situational reminder were shown in the subsets of Figure 3. The NA concentrations of the rostral pons in the methylprednisolone treated rats were found to be $39.24 \pm 10.36 \mathrm{pg} / \mathrm{mg}$ and $22.54 \pm 4.78 \mathrm{pg} / \mathrm{mg}$ in the non-stressed and the stressed rats, respectively; however, this decrease was not found to be statistically significant $(\mathrm{p}=0.1688)$.

NA concentration of metyrapone treated rats decreased in the stressed rats compared to the non-stressed rats being nonsignificant $(77.14 \pm 21.91 \mathrm{pg} / \mathrm{mg}$ vs $44.49 \pm 15.29 \mathrm{pg} / \mathrm{mg}$, respectively, $\mathrm{p}=0.2371)$. 


\section{DISCUSSION}

Noradrenaline is an important neurotransmitter involved in mood, anxiety, learning, and memory functions of the central nervous system. Thus, noradrenaline has been extensively investigated in psychiatric disorders, such as depression, anxiety and PTSD. The role of NA is also studied in the PTSD as the signs and symptoms imply sympathetic hyperactivity $[19,24]$. NA levels in the cerebrospinal fluid were demonstrated to be increased after stress exposure [14]. Previously, in the study of Terzioğlu et al. (2013), NA levels were found to be increased in a parallel fashion with the anxiety indices in rats stressed with a predator scent [16].

We used female Sprague-Dawley rats as in the study of Aykaç et al. (2012) because the female rats were reported to develop more anxiety when compared to the male rats [25]. It was also reported that there are sex differences in stress responses, and women increased the incidence of stress-related psychiatric diseases [26]. Therefore, we used only female rats in this study.

We investigated the effects of methylprednisolone administration on both NA level of the rostral pons and behaviours in a rat model of PTSD since glucocorticoids were shown to exert negative feedback on the HPA axis and stress causes HPA axis activation.

In PTSD studies, there are controversial data regarding the cortisol levels, some data reported the increased circulating cortisol levels, while other data showed a decrease [10-13]. In a study conducted on patients with chronic combat-related PTSD, higher CRF concentrations in the CSF of traumatized patients were found, and researchers concluded that CRF might play a role in arousal disturbances [10]. The urinary cortisol levels were also found to be below the normal range in patients with PTSD [10], and cortisol administration could reduce the symptoms of PTSD in chronic cases [12]. It was also shown that negative feed-back inhibition of ACTH secretion by dexamethasone treatment was more apparent in PTSD patients, where no change was observed control subjects [11]. Low cortisol levels causing increased neuronal CRF transmission that activates CRF/NA circuits -between the CeA and the LC and may produce unopposed autonomic and neuroendocrine responses to stress. As cortisol causes the NA activity to decrease, it may be assumed that low levels of cortisol may make the patients develop PTSD easily [19]. These patients may be unable to restore the increased noradrenergic activity in case of stress [19].
In our experiments, we observed that the increase in the anxiety indices of stressed rats is reversed by methylprednisolone treatment. In PTSD, the automatic recall of memories and decreased cortisol levels may be related, especially during the intrusions. However, it was also demonstrated that administration of glucocorticoids following the memory reactivation results in a decrease in the subsequent recalls $[27,28]$.

NA content is higher in the LC, and it coordinates the structures related with physiopathology of the disease in brain regions, such as the neocortex, the amygdala, the hypothalamus and the hippocampus $[29,30]$. We demonstrated that noradrenergic input in the rostral pons was increased during stress. Although we detected a tendency to decrease in the NA levels in methylprednisolone or metyrapone treated stressed rats, no statistical significance was detected. The discrepancy of this finding may be because we measured the NA content in the rostral pons containing the LC at the end of the experiments. We do not know the time-course change in the NA levels. It might have been reached to a higher level than we had detected. Microdialysis experiments will provide more precise measurements.

Administration of methylprednisolone may inhibit the HPA leading to a decrease in the CRF and consequent reduction in the stimulation of the $\mathrm{LC}$. This may account for the decrease in the NA in the LC following methylprednisolone administration when the stressed rats were exposed to the situational reminder. This effect was not observed with metyrapone administration; in contrast, NA content was increased when compared to methylprednisolone treatment in the stressed rats. The increase in the freezing time duration was observed when the stressed rats were exposed to the reminder. The decreased freezing time may be an indicative sign of adaptive defense response to fear exposure [31-33]. Collectively, we also observed a decrease in the freezing time in the stressed rats following methylprednisolone treatment, and this finding confirms that the corticosteroids stimulate memory consolidation $[34,35]$. The reversal of this effect with the metyrapone experiments also supports the reports regarding the association of glucocorticoids with the strong fear memories in PTSD [36]. The role of corticosteroids in the enhancement of memory consolidation during contextual fear conditioning memory was also shown in many studies [37-39]. 


\section{Conclusion}

Our findings also suggest that glucocorticoids are pharmacologically prophylactic in stress, but the inhibition of the synthesis is not effective in the stress circuitry. We concluded that the anxiety indices and NA levels in the rostral pons increased with the traumatic event. The findings suggest that the methylprednisolone treatment may suppress anxiety through interactions between the LC and the HPA axis.

Ethics Committee Approval: Marmara University Experimental Animal Center (DEHAMER), and local ethical committee approval (22.05.2014, 13, 2013.mar) was obtained before the experiments.

Conflict of Interest: On behalf of all authors, the corresponding author states that there is no conflict of interest.

Financial Disclosure: This work was supported by Marmara University Research Fund [SAG-C-YLP-141014-0347].

Authorship Contributions: Concept - HC, MZG; Design - MZG; Supervision - HC, BA; Fundings - HC; Data collection and/or processing - AMT, BA; Analysis and/or interpretation - BTB, MZG; Writing - BTB; Critical review - MZG.

\section{REFERENCES}

1. Marciniak MD, Lage MJ, Dunayevich E, Russell JM, Bowman L, Landbloom RP, et al. The cost of treating anxiety: the medical and demographic correlates that impact total medical costs. Depress Anxiety 2005;21:178-84. [CrossRef]

2. American Psychiatric Association. Diagnostic and statistical manual of mental disorders, 5th ed. Washington, DC: American Psychiatric Association; 2013. [CrossRef]

3. McEwen BS. Plasticity of the hippocampus: Adaptation to chronic stress and allostatic load. Ann N Y Acad Sci 2001;933:265-77. [CrossRef]

4. Yehuda R. Post-traumatic stress disorder. N Engl J Med 2002;346:10814. [CrossRef]

5. Yehuda R. Status of glucocorticoid alterations in post-traumatic stress disorder. Ann N Y Acad Sci 2009;1179:56-69. [CrossRef]

6. Owens MJ, Nemeroff CB. Physiology and pharmacology of corticotropin-releasing factor. Pharmacol Rev 1991;43:425-73.

7. Valentino RJ, Van Bockstaele E. Convergent regulation of locus coeruleus activity as an adaptive response to stress. Eur J Pharmacol 2008;583:194-203. [CrossRef]

8. Walker DL, Toufexis DJ, Davis M. Role of the bed nucleus of the stria terminalis versus the amygdala in fear, stress, and anxiety. Eur J Pharmacol 2003;463:199-216. [CrossRef]

9. Ludäscher P, Schmahl C, Feldmann RE Jr, Kleindienst N, Schneider M, Bohus M. No evidence for differential dose effects of hydrocortisone on intrusive memories in female patients with complex post-traumatic stress disorder--a randomized, double-blind, placebo-controlled, crossover study. J Psychopharmacol 2015;29:1077-84. [CrossRef]

10. Mason JW, Giller EL, Kosten TR, Ostroff RB, Podd L. Urinary freecortisol levels in posttraumatic stres disorder patients. J Nerv Ment Dis 1986;174:145-9. [CrossRef]

11. Yehuda R, Golier JA, Halligan SL, Meaney M, Bierer LM. The ACTH response to dexamethasone in PTSD. Am J Psychiatry 2004;161:1397-403.
12. Yehuda R, Southwick SM, Krystal, JH, Bremner D, Charney DS, Mason JW. Enhanced suppression of cortisol following dexamethasone administration in posttraumatic stress disorder. Am J Psychiatry 1993;150:83-6. [CrossRef]

13. Bremner JD, Licinio J, Darnell A, Krystal JH, Owens MJ, Southwick SM, et al. Elevated CSF corticotropin-releasing factor concentrations in posttraumatic stress disorder. Am J Psychiatry 1997;154:624-9.

14. Wolf OT. The influence of stress hormones on emotional memory: relevance for psychopathology. Acta Psychol (Amst) 2008;127:513-31.

15. Aston-Jones G, Rajkowski J, Kubiak P, Valentino RJ, Shipley MT. Role of the locus coeruleus in emotional activation. Prog Brain Res 1996;107:379-402. [CrossRef]

16. Terzioğlu B, Kaleli M, Aydın B, Ketenci S, Cabadak H, Gören MZ. Increased noradrenaline levels in the rostral pons can be reversed by $\mathrm{M} 1$ antagonist in a rat model of post-traumatic stress disorder. Neurochem Res 2013;38:1726-33. [CrossRef]

17. Sherin JE, Nemeroff CB. Post-traumatic stress disorder: the neurobiological impact of psychological trauma. Dialogues Clin Neurosci 2011;13:263-78.

18. Page ME, Berridge CW, Foote SL, Valentino RJ. Corticotropin-releasing factor in the locus coeruleus mediates EEG activation associated with hypotensive stress. Neurosci Lett 1993;164:81-4. [CrossRef]

19. Gören MZ, Cabadak H. Noradrenaline and Post-traumatic Stress Disorder. In: Martin, Colin R, Preedy, Victor R, Patel, Vinood B. editors. Comprehensive Guide to Post-Traumatic Stress Disorder. 2016. p.1-16. [CrossRef]

20. Pelow S, Chopin P, File SE, Briley M. Validation of open-closed arm entries in an elevated plus maze as measure of anxiety in the rat. J Neurosci Methods 1985;14:149-67. [CrossRef]

21. Cai WH, Blundell J, Han J, Greene RW, Powell CM. Postreactivation glucocorticoids impair recall of established fear memory. J Neurosci 2006;26:9560-6. [CrossRef]

22. Clay R, Hebert M, Gill G, Stapleton LA, Pridham A, Coady M, et al. Glucocorticoids are required for extinction of predator stress-induced hyperarousal. Neurobiol Learn Mem 2011;96:367-77. [CrossRef]

23. Lowry OH, Rosebrough NJ, Farr AL, Randall RJ. Protein measurement with the Folin phenol reagent. J Biol Chem 1951;193:265-327.

24. Hendrickson RC, Raskind MA. Noradrenergic dysregulation in the pathophysiology of PTSD. Exp Neurol 2016;284:181-95. [CrossRef]

25. Aykaç A, Aydın B, Cabadak H, Gören MZ. The change in muscarinic receptor subtypes in different brain regions of rats treated with fluoxetine or propranolol in a model of post-traumatic stress disorder. Behav Brain Res 2012;232:124-9. [CrossRef]

26. Bangasser DA, Valentino RJ. Sex differences in molecular and cellular substrates of stress. Cell Mol Neurobiol 2012;32:709-23. [CrossRef]

27. Aerni A, Traber R, Hock C, Roozendaal B, Schelling G, Papassotiropoulos A, et al. Low-dose cortisol for symptoms of posttraumatic stress disorder. Am J Psychiatry 2004;161:1488-90. [CrossRef]

28. Schelling G, Kilger E, Roozendaal B, de Quervain DJ, Briegel J, Dagge A, et al. Stress doses of hydrocortisone, traumatic memories, and symptoms of posttraumatic stress disorder in patients after cardiac surgery: a randomized study. Biol Psychiatry 2004;55:627-33. [CrossRef]

29. Vermetten E, Bremner JD. Circuits and systems in stress. II. Applications to neurobiology and treatment in posttraumatic stress disorder. Depress Anxiety 2002;16:14-38. [CrossRef]

30. Sara SJ. The locus coeruleus and noradrenergic modulation of cognition, Nat Rev Neurosci 2009;10:211-23. [CrossRef]

31. Knox D, Fitzpatrick CJ, George SA, Abelson JL, Liberzon I. Unconditioned freezing is enhanced in an appetitive context: implications for the 
contextual dependency of unconditioned fear. Neurobiol Learn Mem 2012;97:386-92. [CrossRef]

32. Rosen JB. The neurobiology of conditioned and unconditioned fear: a neurobehavioral system analysis of the amygdala. Behav Cogn Neurosci Rev 2004;3:23-41. [CrossRef]

33. Roelofs K. Freeze for action: neurobiological mechanisms in animal and human freezing. Philos Trans R Soc Lond B Biol Sci 2017;372. [CrossRef]

34. Kaouane N, Porte Y, Vallée M, Brayda-Bruno L, Mons N, Calandreau L, et al. Glucocorticoids can induce PTSD-like memory impairments in mice. Science 2012;335:1510-3. [CrossRef]

35. Schwabe L, Joëls M, Roozendaal B, Wolf OT, Oitzl MS. Stress effects on memory: an update and integration. Neurosci Biobehav Rev 2012;36:1740-9. [CrossRef]

36. van Zuiden M, Geuze E, Willemen HL, Vermetten E, Maas M,
Amarouchi K, et al. Glucocorticoid receptor pathway components predict posttraumatic stress disorder symptom development: a prospective study. Biol Psychiatry 2012;71:309-16. [CrossRef]

37. Liao Y, Shi YW, Liu QL, Zhao H. Glucocorticoid-induced enhancement of contextual fear memory consolidation in rats: Involvement of D1 receptor activity of hippocampal area CA1. Brain Res 2013;1524:26-33. [CrossRef]

38. Donley MP, Schulkin J, Rosen JB. Glucocorticoid receptor antagonism in the basolateral amygdala and ventral hippocampus interferes with long-term memory of contextual fear. Behav Brain Res 2005;164:197205. [CrossRef]

39. Abrari K, Rashidy-Pour A, Semnanian S, Fathollahi Y, Jadid M. Posttraining administration of corticosterone enhances consolidation of contextual fear memory and hippocampal long-term potentiation in rats. Neurobiol Learn Mem 2009;91:260-5. [CrossRef] 